\title{
Illegal trade of sun bear parts in the Malaysian states of Sabah and Sarawak
}

\author{
Lalita Gomez*, Chris R. Shepherd, Min Sheng Khoo
}

Monitor, PO Box 200, Big Lake Ranch, BC, V0L 1G0, Canada

\begin{abstract}
Malaysia is a known source and consumer of bear bile products in Asia, and sun bears are persistently poached to meet the demand for traditional Chinese medicine (TCM). Surveys of TCM outlets in the East Malaysian states of Sabah and Sarawak were conducted in 2018 and 2019 as part of continuing efforts to monitor the availability of bear bile products in the country. Despite being illegal, the trade in bears and their parts persists, although with fewer TCM outlets offering such products in comparison to numbers reported in previous studies. In $2012,42 \%$ of TCM outlets in Sabah and $35.4 \%$ in Sarawak were found to contain bear bile products. This has since dropped to $35 \%$ in Sabah and 19.3\% in Sarawak in 2018-2019. Gall bladders were the main type of commodity for sale in both states, and were reportedly sourced predominantly by indigenous people. It was evident that most retailers surveyed were aware that the trade in bears and their parts was strictly prohibited, and some traders claim to have stopped selling illegal bear products for this reason. However, some traders who continue to trade in these illegal commodities have become more discreet. These factors contribute to the reduction in TCM outlets observed selling bear bile products. This reduction may also be due to diminishing sun bear populations, as some traders have claimed to have stopped selling bear bile products because of the rarity of or difficulty in procuring genuine bear gall bladders. The threat of illegal trade, combined with loss and degradation of suitable habitat and food resources as well as conflict with humans, puts sun bears at considerable risk. Efforts to mitigate these threats are urgently needed. Reduction of demand for bear parts is essential, as is stronger legal protection, enhanced enforcement and increased community involvement in bear conservation actions to ensure the long-term survival of viable bear populations in Asia.
\end{abstract}

KEY WORDS: Helarctos malayanus $\cdot$ Malaysia $\cdot$ Sun bears $\cdot$ Wildlife trade

\section{INTRODUCTION}

Globally, 8 species of bears exist across Asia, Europe, North America and South America. Asia is home to 6 of these species, with 4 species, Asiatic black bear Ursus thibetanus, sun bear Helarctos malayanus, sloth bear Melursus ursinus and giant panda Ailuopoda melanoleuca, endemic to the region and 2 others, brown bear Ursus arctos and polar bear Ursus maritimus, found across a broader range. All 4 bear species endemic to Asia are threatened with extinction as assessed by the IUCN Red List of Threat-

${ }^{*}$ Corresponding author: lalita.gomez@mcrsociety.org ened Species (Scotson et al. 2017). Asian bear species are considered to be in decline across their range, in part due to habitat loss, but increasingly due to the illegal and widespread poaching and killing of bears fueled by a black-market trade in live bears, their parts and derivatives (Shepherd \& Nijman 2008, Foley et al. 2011, Burgess et al. 2014, Lee et al. 2015, Wilcox et al. 2016, Nijman et al. 2017, Or et al. 2017, Gomez \& Shepherd 2018, Crudge et al. 2020).

Bears are targeted for their gall bladder or bile used in traditional Chinese medicines (TCM), for their meat (and especially paws) coveted by specialised

() The authors 2020. Open Access under Creative Commons by Attribution Licence. Use, distribution and reproduction are unrestricted. Authors and original publication must be credited. 
wild meat restaurants, their parts (e.g. claws, teeth, skull, skin) prized as trophies, and, increasingly, live for the exotic pet trade. This demand has also fueled the establishment of bear farms in some parts of Asia; these farms arguably have no conservation benefit as most of these facilities continuously rely on wildcaught bears that are captured throughout the region, and due to consumer preference for bile extracted from wild-caught animals (Livingstone \& Shepherd 2014, Willcox et al. 2016, Crudge et al. 2020). Malaysia plays a key role in the illegal trade of bears, as a source and consumer of bear parts and products (Mills \& Servheen 1994, Pereira et al. 2002, Foley et al. 2011, Burgess et al. 2014, Lee et al. 2015).

The smallest and least understood of the Asian bear species is the sun bear (Crudge et al. 2019). Globally, sun bears are assessed as Vulnerable on the IUCN Red List of Threatened Species, with populations considered to be in decline throughout their range (Fig. 1) (Scotson et al. 2017). This decline is largely attributed to deforestation and high levels of poaching for commercial trade (Wong 2006, Shepherd \& Nijman 2008, Foley et al. 2011, Wilcox et al.

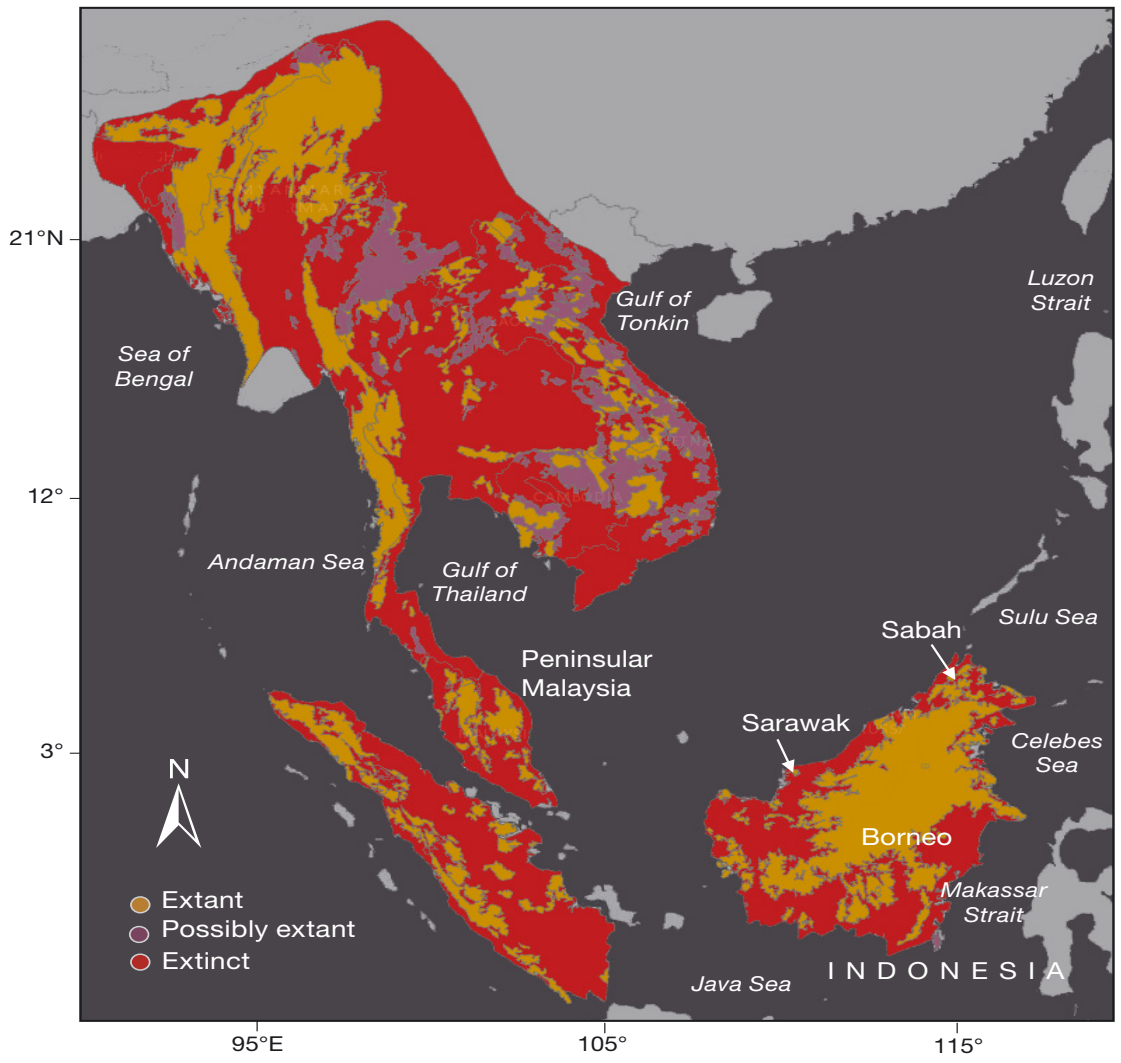

Fig. 1. Range map of sun bears extracted from the IUCN Red List of Threatened Species (Scotson \& Fredriksson 2016). Our study was undertaken in East Malaysia, i.e. the States of Sabah and Sarawak located on the island of Borneo, which also encompasses Brunei Darussalam and Kalimantan, Indonesia
2016, Nijman et al. 2017, Gomez \& Shepherd 2018, Livingstone et al. 2018, Crudge et al. 2020). While the status of sun bear populations is largely unknown, they are generally considered to be more abundant or common in the southern regions of their range (e.g. Indonesia and Malaysia), rare in the other regions (e.g. Bangladesh, Cambodia, India, Lao PDR, Myanmar, Thailand and Viet Nam), and extinct in Singapore and possibly China (Scotson et al. 2017).

Sun bears are the only bear species native to Malaysia and occur as 2 subspecies: Helarctos malayanus malayanus, which is found in Peninsular Malaysia, and H. m. euryspillus, found in the States of Sabah and Sarawak, on the island of Borneo. Estimations by the Malaysian Department of Wildlife and National Parks put sun bear populations in Malaysia at between 300 and 500 individuals as of 2018 (The Star Online 2019). The sun bear is a protected species across Malaysia, and therefore any trade in the species, their parts or derivatives is strictly illegal. Conservation efforts to end the illegal trade in bears, their parts and derivatives in Malaysia have been ongoing for over 20 yr (Gomez 2019). Systematic surveys undertaken to monitor the extent of the trade and to identify areas with high levels of open availability of bear parts and derivatives in retail outlets have been continuous since 2010 (Foley et al. 2011, Burgess et al. 2014, Lee et al. 2015). Information obtained from these surveys has been provided to the relevant authorities for enforcement action, and to the Federation of Chinese Physicians and Medicine Dealers Associations of Malaysia, in the hope that the federation itself would start regulating its members to ensure no illegal trade was taking place. Awareness raising activities have also been held with TCM practitioners in Malaysia to highlight the illegality of prescribing medicine that contains protected species and encouraging them to protect their reputation by practicing TCM within the confines of local laws.

From 2012 to November 2019, there were at least 32 seizures of sun bears in Malaysia, most of which occurred in Sabah (14 incidents) and involved both live bears and parts (gall bladders, paws, teeth and skin). Aside from seizures, there were at least 6 cases in Sabah (2016-2017) involving 
10 bears found butchered with their paws and gall bladders missing or found injured from snares and hunting spears (Or et al. 2017). In Sarawak, the hunting and killing of bears has been openly posted on Facebook, bear meat has been found for sale in local markets, live bears are being kept as pets, and skins have been seized from local and foreign poachers (Krishnasamy \& Shepherd 2014, Balakrishnan 2016, Chu 2017, Then 2019, Veno 2019). Despite efforts to mitigate against the trafficking of sun bears in Malaysia, it is clear that illegal trade continues to put bear populations at risk.

In 2017, the IUCN SSC Bear Specialist Group, Free the Bears and TRAFFIC Southeast Asia organised the 1st International Symposium on Sun Bear Conservation and Management to gather the collective knowledge and opinions from sun bear experts relevant to the conservation of this species. Information gathered from this symposium was then used to develop a 10-yr range-wide conservation action plan specifically for sun bears (Crudge et al. 2019). It outlines a strategic approach for priority actions identified as key in ensuring wild sun bear populations remain an ecologically functioning component across their range. The plan has 5 main goals, one of which is aimed at eliminating illegal exploitation of the species. A primary objective under this goal is to 'improve law enforcement effectiveness for laws pertaining to hunting, trade and use of sun bears and their parts' (Crudge et al. 2019) and encompasses continued monitoring and investigation of availability of sun bear parts and products to support law enforcement action.

In conjunction with this goal, the objective of this study was examine the illegal trade of bears used in the TCM industry in Sabah and Sarawak to (1) assess current levels of availability of sun bear parts and derivatives to support law enforcement action; and (2) understand current trends in trade and levels of awareness amongst retailers, in comparison to past studies undertaken, in order to aid in the development of further bear conservation interventions and to catalyse targets and effective enforcement actions.

\section{MATERIALS AND METHODS}

A physical market survey was undertaken from December 2018 to February 2019 in key locations (i.e. cities and towns) across the Malaysian states of Sabah and Sarawak (Fig. 1, Table 1). This encompassed 13 locations in Sabah and 11 locations in Sarawak. At each location, a search was made for TCM outlets
Table 1. The number of locations surveyed in Sabah and Sarawak and the number of traditional Chinese medicine (TCM) outlets visited at each location between December 2018 and February 2019

\begin{tabular}{|c|c|c|c|c|}
\hline \multirow[t]{2}{*}{ No. } & \multicolumn{2}{|c|}{ Sabah } & \multicolumn{2}{|c|}{ Sarawak } \\
\hline & Location & $\begin{array}{l}\text { No. TCM } \\
\text { outlets } \\
\text { surveyed }\end{array}$ & Location & $\begin{array}{l}\text { No. TCM } \\
\text { outlets } \\
\text { surveyed }\end{array}$ \\
\hline 1 & Beaufort & 2 & Bintangor & 3 \\
\hline 2 & Keningau & 2 & Bintulu & 9 \\
\hline 3 & Kota Kinabalu & 12 & Kanowit & 1 \\
\hline 4 & Kota Marudu & 2 & Kapit & 1 \\
\hline 5 & Labuan & 1 & Kuching & 17 \\
\hline 6 & Lahad Datu & 4 & Lawas & 2 \\
\hline 7 & Penampang & 2 & Limbang & 3 \\
\hline 8 & Ranau & 1 & Miri & 18 \\
\hline 9 & Sandakan & 9 & Sarikei & 3 \\
\hline 10 & Sepitang & 1 & Sibu & 23 \\
\hline 11 & Tawau & 6 & Sri Aman & 3 \\
\hline 12 & Tenom & 2 & & \\
\hline 13 & Tuaran & 1 & & \\
\hline
\end{tabular}

and, once identified, a local consultant posing as a potential customer would visit the outlet to enquire about the availability of bear gall bladder or bear bile products for sale. When such products were offered, the consultant gathered additional data on quantity, origin, price and demand, as well as their understanding of legality of the product on sale through an informal discussion with the TCM retailers (although it should be noted that this depended on the traders' willingness to provide such details, which was not always the case). Bear parts and products observed for sale in TCM outlets were assumed to be genuine where reported as such by a retailer. Verification of the products on sale was not possible as no products were purchased as part of this study. TCM outlets found selling or claimed to be selling bear gall bladders and derivatives were reported to the relevant enforcement agencies for their further action.

The conversion of prices from MYR to USD was based on https://www1.oanda.com/currency/converter/, as of 22 July 2019.

\section{RESULTS}

\subsection{Availability}

A total of 128 TCM outlets in 24 locations across Sabah and Sarawak were surveyed (Table 1). Bear parts and derivatives were recorded for sale in $25 \%$ of TCM outlets surveyed but in more than half of the locations visited $(54.2 \%)$. In Sabah, bear parts and derivatives were found for sale in 9 of the 13 locations 
$(69.2 \%)$ visited (i.e. Beaufort, Keningau, Kota Kinabalu, Kota Marudu, Lahad Datu, Ranau, Sandakan, Tawau, Tenom and Tuaran) and in 16 of the 45 TCM outlets surveyed (35\%) (Fig. 2). In Sarawak, only 4 of the 11 locations $(36.4 \%)$ visited were recorded with bear parts and derivatives for sale, i.e. Bintulu, Kuching, Miri and Sibu, as were 16 of the 83 TCM outlets (19.3\%) surveyed (Fig. 2).

\subsection{Forms of bear product}

The main type of bear product observed for sale in both Sabah and Sarawak was gall bladder, with a minimum of 79 whole gall bladders recorded in 25 TCM outlets in both states combined. The majority of these were found in Sarawak ( $\mathrm{n}=53$ whole gall bladders in 15 TCM outlets) in 3 main locations, Miri ( $\mathrm{n}=$ 25), Kuching ( $\mathrm{n}=19)$ and Bintulu $(\mathrm{n}=9)$. In Sabah, 26 gall bladders were observed for sale in 10 TCM out- lets in 7 locations, the majority in Beaufort $(\mathrm{n}=11)$, followed by Sandakan ( $\mathrm{n}=5)$, Tawau $(\mathrm{n}=3)$, Kota Kinabalu ( $\mathrm{n}=2)$, Keningau $(\mathrm{n}=1)$, Ranau $(\mathrm{n}=1)$ and Tenom $(n=1)$. Five traders claimed to have gall bladders but refused to reveal them. In these instances we assumed these traders to be in possession of at least one whole gall bladder. Aside from whole gall bladders, one Sabah-based trader sold gall bladder in vials containing shredded pieces of gall bladder, and one Sabah-based trader sold it as wine, i.e. gall bladder soaked in wine. The price of gall bladders ranged widely. In Sabah, gall bladder prices ranged between MYR300 and 1000 per gall bladder ( USD73-243) or were priced per kilogram (MYR180 [USD44] per $11 \mathrm{~g}$ or MYR300 [USD73] per $18 \mathrm{~g}$ ). In Sarawak, prices ranged between MYR50 and 1900 per gall bladder ( USD12-462). Shredded gall bladder was being sold at MYR80 per vial ( USD20) while bear bile wine was being sold at MYR60 per $30 \mathrm{ml}$ ( USD15).

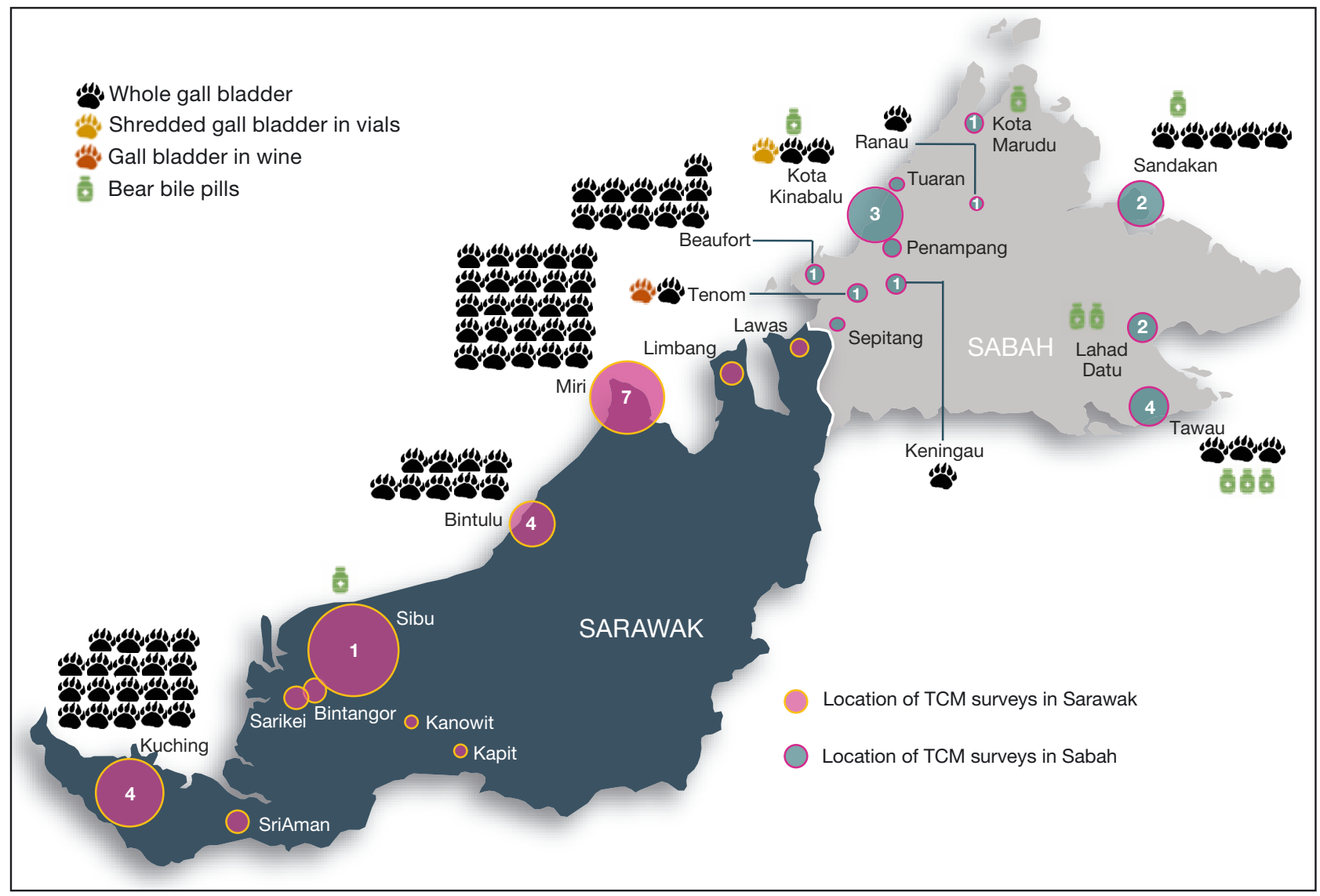

Fig. 2. Location of surveys undertaken in main cities and towns in Sabah and Sarawak between December 2018 and February 2019. The size of the circles represents survey effort at each location based on the number of traditional Chinese medicine (TCM) outlets visited (as presented in Table 1) and the number within each circle represents the number of TCM outlets that were observed with bear parts and derivatives for sale. The number of symbols for gall bladder and bear bile represents the number of the respective bear part or derivative found at these locations. An additional location not marked on the map is the island of Labuan, off the coast of Sabah, where 1 TCM outlet was visited but no bear parts or derivatives were found for sale 
The only other bear products observed for sale were pills (pure or mixed with herbs or pearl powder), found in 9 TCM outlets ( $\mathrm{T}=8$ in Sabah; $\mathrm{n}=1$ in Sarawak). Four traders ( $\mathrm{n}=3$ in Sabah, 1 in Sarawak) claimed to be uncertain of the content of the pills, stating they consisted mostly of plant-based material, with one of these traders further noting that even if they did contain bear bile, it was likely to be in very low quantities. One trader claimed to have pure bear bile pills that were made from the bile of polar bears, and offered to source for other bear-based ointment from Hong Kong. The pills were priced at MYR0.50 per pill $(\sim$ USD0.12) in Sarawak and between MYR0.50 and 1.20 per pill ( USD0.12-0.30) in Sabah, or between MYR37.70 and 90 per bottle (100 pills) ( USD9-22).

\subsection{Source/demand}

Nineteen traders reported that indigenous peoples were the main source of gall bladders to TCM outlets in both Sabah and Sarawak, but that the supply was irregular. One trader in Sarawak claimed the gall bladders he was selling were from Indonesia. The pills were reportedly sourced from Peninsular Malaysia ( $\mathrm{n}=3$ TCM outlets), China ( $\mathrm{T}=1$ TCM outlet) and Thailand ( $\mathrm{n}=1$ TCM outlet).

Most traders $(76 \%)$, regardless of whether they were selling bear bile products, were aware that it is illegal to sell bear parts and derivatives. Of the traders recorded selling bear parts, 7 claimed to keep bear gall bladders for their own personal use but on occasions sold these to trusted customers if it meant saving a life. Five traders noted that it is illegal to keep gall bladders in the shop and either kept these out of sight or at a different location, e.g. at home. A further 4 traders in Sabah claimed that it is legal to keep bear gall bladders provided it is for personal use. Some traders $(n=17)$ also claimed to be only selling the last of their stock. In Sarawak, 4 traders reportedly sold bear bile products to Chinese nationals looking specifically for bear gall bladder, with one trader claiming this is done through an agent who buys and takes the gall bladders to China.

Of the traders not found with bear products for sale ( $\mathrm{n}=67$ in Sarawak, $\mathrm{n}=29$ in Sabah), 13 traders cited reasons such as it is illegal, or it was too risky for too little profit, while a further 17 traders cited being unable to distinguish between real and fake gall bladders as the main reason, with 10 of these traders stating that most gall bladders in the market are likely to be fake. It was also stated that bears were becoming harder to find and that indigenous people were substituting genuine products with the gall bladders of other animals, such as pigs. That said, there were 3 traders who expressed a willingness to source gall bladders if required and on a few occasions, provided contact details for middlemen that they thought could source for genuine bear gall bladders. Seven traders offered pills when asked for bear gall bladder but noted that the pills were purely herbal in nature (and as such, we consider this as not selling bear bile products). Only one trader in Sibu, Sarawak, claimed to have stopped selling bear gall bladder due to a lack of demand.

\section{DISCUSSION}

This study confirms that sun bears are still being hunted for use in TCM in Malaysia, despite this trade being strictly illegal. With observations of availability of bear parts in more than half of the locations surveyed in Sabah and Sarawak, this demand remains a significant threat to the species. Sun bears are being targeted for their gall bladders, the most commonly observed bear commodity in both Sabah and Sarawak. These results are similar to the findings of previous studies in Malaysia (Mills \& Servheen 1994, Pereira et al. 2002, Foley et al. 2011, Burgess et al. 2014, Lee et al. 2015, Gomez 2019), which indicates that conservation initiatives to mitigate this threat have not yet been successful. Enforcement efforts have also had insufficient impact in eradicating this illegal trade. Sun bears are reported to be in decline across their range, with an estimated $\sim 35 \%$ decline over the past $30 \mathrm{yr}$ and a predicted decline of more than $40 \%$ over the next 30 yr (Scotson et al. 2017). The Sundaic Region, covering Indonesia, mainland Peninsular Malaysia and the island of Borneo, is described as having the highest abundance and population density of sun bears, although this is based on historical estimates and data (Crudge et al. 2019). Whether this remains true is questionable, considering that bears are persistently being hunted and killed for their parts throughout Indonesia and Malaysia (Gomez \& Shepherd 2019, Gomez et al. 2019).

While the illegal trade in bear parts and derivatives is far from being eradicated in these 2 Malaysian states, there has been an apparent reduction in the number of TCM outlets offering bear bile parts and products. In 1997, Meijard (1999) reported that 6 of the 10 TCM shops they surveyed in Sarawak had gall bladders in stock, whereas in Sabah it was more discreet, with traders reporting they were prohibited 
from selling protected species. In 2001, TCM shops were surveyed by the World Society for the Protection of Animals (WSPA), across several states in the country for trade in bears and their parts (Pereira et al. 2002). They found that $75 \%$ of outlets in Kota Kinabalu, Sabah, and $53 \%$ of outlets in Kuching, Sarawak, were found to contain gall bladders, bear bile powders and other medicines manufactured out of bear bile. Over 90 gall bladders were observed for sale. In 2010-2011, 38\% of TCM outlets surveyed in Sabah and $28 \%$ in Sarawak were found to be selling bear parts (Foley et al. 2011). Surveys in 2012 saw a decline in open availability in Sabah $42.9 \%$ of TCM outlets surveyed had bear parts for sale) but a slight increase in Sarawak (35.4\% of TCM outlets had bear parts for sale) (Lee et al. 2015). The present study shows further declines in Sabah $35 \%$ of TCM outlets had bear parts for sale) and a significant decrease in Sarawak $(19.3 \%$ of TCM outlets had bear parts for sale). Similarly, the number of gall bladders encountered for sale has dropped since 2012. A total of 72 TCM outlets in Sabah and Sarawak were surveyed in 2012 and 117 whole gall bladders were observed for sale, in comparison to a total of 128 TCM outlets surveyed and 79 whole gall bladders in 2019. This was largely attributed to fewer gall bladders observed for sale in Sarawak (i.e. 53 gall bladders in comparison to 93 in 2012), whereas in Sabah, 26 whole gall bladders were found in 2019 compared to 25 gall bladders in 2012.

The reduction in open availability of bear products could be attributed to a multitude of factors. There has been increased awareness on the illegality of trading in bears, their parts and derivatives in Malaysia, which has pushed the trade underground, or possibly online. Over the past $20 \mathrm{yr}$, a number of studies have been undertaken, resulting in publications and media coverage to draw attention to the illegal nature of the trade in bears in Malaysia and to highlight potential impacts of trade on wild bear populations. These data are evidence of illegal trade activities and have thus been used to support law enforcement action and to raise awareness with the TCM community and the public. These measures have had some positive impact: we know most traders in Malaysia are currently aware that sun bears are a protected species and that the trade in their parts or derivatives is prohibited by law; fewer traders were observed with bear products for sale. However, some traders continuing to trade in illegal commodities have become more discreet. This is exemplified by some traders who were unwilling to show their stock of bear gall bladders or claimed to keep their stock elsewhere, a factor also noted by Lee et al. (2015) particularly in reference to the sale of bear gall bladders (i.e. not on open display, hidden in different rooms, or stored in a different location altogether). This is not surprising considering that wildlife traffickers are continuously adapting or finding alternative means to meet black market demands. Heinrich et al. (2017) found that the global trafficking of pangolin scales involved highly mobile networks that used 27 new global trade routes annually. Wildlife traders in Asia are also increasingly moving from physical markets to online platforms, which are harder to police and monitor and afford greater anonymity (Derraik \& Phillips 2010, IFAW 2011, Lavorgna 2014, Harrison et al. 2016a).

Another factor that needs to be considered is the possibility that the decline in open availability may be a sign that the hunting and trade of bears is reducing sun bear populations in Malaysia, a case in point being the proclamations of many TCM traders on the rarity of or difficulty in procuring genuine bear gall bladders. Studies in Sabah and Sarawak show that wildlife declines are increasingly due to poaching more so than deforestation (Brodie et al. 2015, Voigt et al. 2018). In one seizure incident alone, as recently as October 2019, over 800 wildlife parts were found in Sarawak, of which 183 were bear gall bladders (Ling 2019). This is also reflected elsewhere in Southeast Asia, where indiscriminate and illegal use of snares is decimating vertebrates across the region, including bears (Harrison et al. 2016b, Gray et al. 2018, Symes et al. 2018, Tilker et al. 2019). In Cambodia, seizure rates involving bears have reportedly decreased in recent years and this is thought to be due to declining bear populations, in addition to trade becoming more discreet (Crudge et al. 2019). Population declines of bears in Viet Nam have been attributed to intense hunting and trapping that coincided with the rise of bear bile farming in the country (Crudge et al. 2016). Similar findings were reported in Myanmar, where intense and targeted hunting resulted in declines of both Asiatic black bear and sun bear populations in the Imawbum Mountains, primarily attributed to demand from China (Nijman et al. 2017). With bear populations depleting in other parts of Asia where they are in high demand, this also exacerbates the threat in countries and neighbouring regions that still have wild bears. At least 4 traders in Sarawak claimed to sell bear bile products to Chinese nationals. China and Viet Nam have been reported as key drivers in the poaching of bears for traditional medicine and exotic meat in Cambodia, Indonesia, Lao PDR, Myanmar, Thailand and Russia 
(Burgess et al. 2014, Nijman et al. 2017, Livingstone et al. 2018). During a national crackdown on poaching and trafficking of wildlife throughout Malaysia in 2019, at least 44 foreign nationals were arrested in connection with these crimes, namely from Bangladesh, Cambodia, China, Indonesia, Myanmar, Thailand and Viet Nam (TRAFFIC 2019).

It is clear that TCM traders are largely aware of the illegality of selling protected species, and while some may have genuinely stopped selling bear parts and derivatives for this very reason, there are others who continue to flout local wildlife laws to feed the demand for such products. International trade regulations are also being violated, with the reported trafficking of bear parts and products to and from Malaysia involving China, Indonesia and Thailand. Sun bears are listed in Appendix I of CITES, and international commercial trade such as this is prohibited. Sun bears are a 'totally protected' species under the Sabah Wildlife Conservation Enactment, and penalties for offences involving 'totally protected' species include fines of between MYR50K and 250K ( USD12K-60K) and imprisonment from 1 to $5 \mathrm{yr}$. Despite numerous crimes against bears in Sabah (Or et al. 2017), only 2 people have been prosecuted over the years: one was sentenced to $2 \mathrm{yr}$ in jail and a fine of MYR50K ( USD12K), while the other is still pending an appeal (Jeffrey 2019). The Sarawak Wildlife Protection Ordinance is weak for bears that are only listed as 'protected', a category that allows for the hunting of bears with a permit, as opposed to 'totally protected' status, which prohibits any hunting. Further, the penalties are low, with fines of up to MYR10K ( USD2400) and imprisonment of up to $1 \mathrm{yr}$. Such weak legal protection and low monetary fines impede conservation efforts. Weak legislation also fails to empower enforcement authorities or judiciary in taking affirmative action against illegal wildlife traders. From September to November 2019 alone, there were at least 6 incidents concerning sun bears in Sarawak, involving the seizure of either live bears or meat and gall bladders. But seizure of wildlife parts is not sufficient, and if not in conjunction with arrests and strong prosecution, has limited impact as a deterrent. It is therefore essential that the Sarawak government strengthens current legislation and affords sun bears full protection, which will enhance efforts made by authorities to end this trade. This measure was proposed to the Sarawak government in 1997 within a Master Plan for Wildlife in Sarawak (Krishnasamy \& Shepherd 2014), and yet more than $20 \mathrm{yr}$ have passed and this recommendation has yet to be implemented.
Efforts to engage the indigenous community through education and awareness programs, capacity building or alternative livelihood solutions is also urgently required to reduce their role and exploitation in the illicit sourcing of wildlife products. Currently, local wildlife laws are such that indigenous people are given rights to hunt certain species for their own personal use but not for commercial purposes. Nevertheless, these rights are being exploited by wildlife traders and this has serious implications for all wildlife species. During the present study, aside from bear parts, pangolin scales, hornbill casques and rhino horn, all 'totally protected' species, were also observed for sale in TCM outlets. While enhanced enforcement against poachers and hunters is crucial, the importance of engaging local communities that live near wildlife is also seen as essential in complementing enforcement efforts to disrupt the illegal exploitation of wildlife (Challender \& MacMillan 2014, Hubschle \& Shearing 2018, Roe \& Booker 2019). As noted in Hubschle \& Shearing (2018), local communities are more likely to support illegal wildlife trade or poaching activities if they remain on the margins of protected areas and are excluded from the economic benefits of conservation. Such initiatives have had some measure of success with indigenous communities in Kinabatangan, Sabah (Ancrenaz et al. 2007), local communities in India and Nepal (Pathak 2006), and traditional herding communities in China (Foggin 2018).

Lastly, the Sun Bear Conservation Action Plan (2019-2028) calls for the elimination of illegal exploitation of sun bears through the reduction of demand for live bears, their parts and products. The degree to which consumers knowingly or unwittingly contribute to this demand or their motivations is an aspect that has yet to be thoroughly investigated and addressed in Malaysia (Gomez 2019). Aside from a preliminary survey of attitudes and awareness of the bear bile trade carried out in 2013, little has been done to understand and address the demand (Lee et al. 2015). We reiterate here the urgent need for more detailed evidence-based research to better understand consumer behavior and develop and implement appropriate consumer behavior and a demandreduction strategy in Malaysia.

\section{CONCLUSIONS}

Our study shows that sun bears are still being hunted and exploited for use in TCM in the Malaysian states of Sabah and Sarawak, and that this remains a persistent threat to wild bear populations. 
The threat of illegal trade, combined with loss and degradation of suitable habitat and food resources as well as conflict with humans, puts sun bears at considerable risk. Efforts to mitigate these threats are urgently needed. Enhanced enforcement efforts, stronger legislation, increased local engagement and a significant reduction in demand for bear parts are all essential actions that must be taken to ensure the long-term survival of viable bear populations in Asia.

Acknowledgements. Many thanks to the reviewers for their invaluable feedback, which helped improve an earlier draft of this paper. We also owe a great deal of thanks to Hauser Bears, who continuously and generously support our efforts to end the illegal trade of bears in Asia.

\section{LITERATURE CITED}

Ancrenaz M, Dabek L, O'Neil S (2007) The costs of exclusion: recognising a role for local communities in biodiversity conservation. PLOS Biol 5(11):e289

Balakrishnan N (2016) Malayan sun bears are being brutally slaughtered in Sarawak. https://says.com/my/news/sunbears-are-getting-slaughtered-in-sarawak (accessed 20 Jun 2019)

Bedi RS (2019) Perhilitan still taking statement of singer who kept sun bear in apartment. The Star Online. www.the star.com.my/news/nation/2019/06/10/perhilitan-stilltaking-statement-of-singer-who-kept-sun-bear-in-apart ment/\#mueZL2ug6boGlqcC.99 (accessed 10 Jun 2019)

Brodie JF, Giordano AJ, Zipkin EF, Bernard H, Mohd-Azlan J, Ambu L (2015) Correlation and persistence of hunting and logging impacts on tropical rainforest mammals. Conserv Biol 29:110-121

Burgess EA, Stoner SS, Foley KE (2014) Bring to bear: an analysis of seizures across Asia (2000-2011). TRAFFIC, Petaling Jaya, Selangor

Challender DWS, MacMillan DC (2014) Poaching is more than an enforcement problem. Conserv Lett 7:484-494

Chu MM (2017) Black day for animal lovers in Malaysia (graphic content). The Star Online. https://www.thestar. com.my/news/nation/2017/12/25/black-day-for-animallovers-in-malaysia-graphic-content/\#XMKXI4DUEm ZiubF2.99 (accessed 20 Jun 2019)

Crudge B, Wilkinson NM, Do VT, Cao TD, Cao TT, Weegenaar A, Hunt M (2016) Status and distribution of bears in Vietnam, 2016. Tech Rep, Free the Bears/Animals Asia, Vietnam

Crudge B, Lees C, Hunt M, Steinmetz R, Fredriksson G, Garshelis D (eds) (2019) Sun bears: global status review \& conservation action plan, 2019-2028. IUCN SSC Bear Specialist Group/IUCN SSC Conservation Planning Specialist Group/Free the Bears/TRAFFIC

* Crudge B, Nguyen T, Cao TT (2020) The challenges and conservation implications of bear bile farming in Viet Nam. Oryx 54:252-259

Derraik JGB, Phillips S (2010) Online trade poses a threat to biosecurity in New Zealand. Biol Invasions 12:1

Foggin JM (2018) Environmental conservation in the Tibetan Plateau Region: lessons for China's belt and road initiative in the mountains of Central Asia. Land 7:52

Foley KE, Stengel CJ, Shepherd CR (2011) Pills, powders, vials and flakes: the bear bile trade in Asia. TRAFFIC,
Petaling Jaya, Selangor

Gomez L (2019) An update on the bear bile trade in Peninsular Malaysia. TRAFFIC, Southeast Asia Regional Office, Petaling Jaya

Gomez L, Shepherd CR (2018) Trade in bears in Lao PDR with observations from market surveys and seizure data. Glob Ecol Conserv 15:e000415

Gomez L, Shepherd CR (2019) Bearly on the radar-an analysis of seizures of bears in Indonesia. Eur J Wildl Res 65(6)

Gomez L, Shepherd CR, Morgan M (2019) Revealing the online trade of sun bears in Indonesia. Traffic Bull 31(2)

* Gray TNE, Hughes AC, Laurance WF, Long B, and others (2018) The wildlife snaring crisis: an insidious and pervasive threat to biodiversity in Southeast Asia. Biodivers Conserv 27:1031-1037

*Harrison JR, Roberts DL, Hernandez-Castro JC (2016a) Assessing the extent and nature of wildlife trade on the darkweb. Conserv Biol 30:900-904

*Harrison RD, Sreekar R, Brodie JF, Brook S and others (2016b) Impacts of hunting on tropical forests in Southeast Asia. Conserv Biol 30:972-981

Heinrich S, Whittman TA, Ross JV, Shepherd CR, Challender DWS, Cassey P (2017) The global trafficking of pangolins: a comprehensive summary of seizures and trafficking routes from 2010-2015. TRAFFIC, Southeast Asia Regional Office, Petaling Jaya

Hubschle A, Shearing C (2018) Ending wildlife trafficking: local communities as change agents. The Global Initiative Against Transnational Organised Crime, Switzerland

IFAW (International Fund for Animal Welfare) (2011) Killing with keystrokes 2.0: IFAW's investigation into the European online ivory trade. https://bit.ly/2H4u61Q

Krishnasamy K, Shepherd CR (2014) A review of the sun bear trade in Sarawak, Malaysia. Traffic Bull 26:37-40

Jeffrey S (2019) Armed unit to tackle poaching. Daily Express. www.dailyexpress.com.my/news/145475/armed-unit-totackle-poaching/ (accessed 27 Dec 2019)

Lavorgna A (2014) Wildlife trafficking in the internet age. Crime Science 2014(3):15

Lee SL, Burgess EA, Chng SCL (2015) Hard to bear: an assessment of trade in bear bile and gall bladder in Malaysia. TRAFFIC, Petaling Jaya, Selangor

KLing S (2019) Wildlife parts seized in Sarawak. The Star Online. www.thestar.com.my/news/nation/2019/10/10/ wildlife-parts-seized-in-swak (accessed 10 Jun 2019)

* Livingstone E, Shepherd CR (2014) Bear farms in Lao PDR expand illegally and fail to conserve wild bears. Oryx 50: $1-9$

Livingstone E, Gomez L, Bouhuys J (2018) A review of bear farming and bear trade in Lao People's Democratic Republic. Glob Ecol Conserv 13:e00380

Meijard E (1999) Human imposed threats to sun bears in Borneo. Ursus 11:185-192

Mills J, Servheen C (1994) The Asian trade in bears and bear parts. TRAFFIC USA

Nijman V, Oo H, Shwe NM (2017) Assessing the illegal bear trade in Myanmar through conversations with poachers: topology, perceptions and trade links to China. Human dimensions of wildlife. Traffic Bull 27:44-46

Or OC, Gomez L, Lau CF (2017) Recent reports of sun bear seizures and poaching in Malaysia. International Bear News, Summer 2017, Vol 26, No. 2

Pathak N (2006) Community conserved areas in South Asia. Parks, Community Conserved Areas 2006, Vol 16, No 1

Pereira D, Loh R, Bonfiglio MB (2002) The bear trade in Malaysia: the bear gall bladder and bear bile trade in tra- 
ditional Chinese medicine shops in Malaysia. WPSA, UK; www.worldanimalprotection.ca/sites/default/files/media/ ca_-_en_files/bearbilemalaysia_tcm22-2714.pdf

Roe D, Booker F (2019) Engaging local communities in tackling illegal wildlife trade: a synthesis of approached and lessons for best practice. Conserv Sci Practice 2019:e26

Scotson L, Fredriksson G (2016) Helarctos malayanus. The IUCN Red List of Threatened Species. Version 2019-3

Scotson L, Fredriksson G, Augeri D, Cheah C, Ngoprasert D, Wai-Ming W (2017) Helarctos malayanus (errata version published in 2018). The IUCN Red List of Threatened Species 2017: e.T9760A123798233 (downloaded 20 Aug 2018)

Shepherd CR, Nijman V (2008) The trade in bear parts from Myanmar: an illustration of the ineffectiveness of enforcement of international wildlife trade regulations. Biodivers Conserv 17:35-42

Symes WS, Edwards DP, Miettinen J, Rheindt FE, Carrasco $\mathrm{R}$ (2018) Combined impacts of deforestation and wildlife trade on tropical biodiversity are severely underestimated. Nat Commun 9:4052

Then S (2019) Illegal wildlife farm in Sibu busted. The Star Online. www.thestar.com.my/news/nation/2019/10/17/ illegal-wildlife-farm-in-sibu-busted (accessed 12 Dec 2019)

Editorial responsibility: $K$. Anna Nekaris,

Oxford, UK
Tilker A, Abrams, JF, Mohamed A, Nguyen A and others (2019) Habitat degradation and indiscriminate hunting differentially impact faunal communities in the Southeast Asian tropical biodiversity hotspot. Commun Biol 2:396

TRAFFIC (2019) Malaysia's newly launched enforcement operation showing promising results to protect wildlife. https://www.traffic.org/news/malaysias-newly-launchedenforcement-operation-showing-promising-results-toprotect-wildlife/ (accessed 2 Jan 2020)

*Veno J (2019) Sun bear rescued from longhouse in Betong. Borneo Post. https://www.theborneopost.com/2019/11/14 /sun-bear-rescued-from-longhouse-in-betong/ (accessed 12 Dec 2019)

Voigt M, Wich SA, Ancrenaz M, Meijaard E, and others (2018) Global demand for natural resources eliminated more than 100,000 Bornean orangutans. Curr Biol 28: 761-769

Willcox D, Minh NDT, Gomez L (2016) An assessment of trade in bear bile and gall bladder in Viet Nam. TRAFFIC, Petaling Jaya, Selangor

Wong ST (2006) The status of Malayan sun bear in Malaysia. In: Japan Bear Network (compiler) Understanding Asian bears to secure their future. Japan Bear Network, Ibaraki, p 66-72

Submitted: August 14, 2019; Accepted: February 3, 2020

Proofs received from author(s): February 27, 2020 